\title{
BMJ Open Premedication practices for tracheal intubation in neonates transported by French medical transport teams: a prospective observational study
} Ricardo Carbajal (D , ${ }^{1,2}$ Noella Lode ${ }^{3}$ Azzedine Ayachi, ${ }^{4}$ Ourida Chouakri, ${ }^{5}$
Véronique Henry-Larzul, ${ }^{6}$ Katia Kessous, ${ }^{3}$ Audrey Normand, ${ }^{7}$ Emilie Courtois,
Jessica Rousseau, ${ }^{8}$ Patricia Cimerman, ${ }^{10}$ Jean-Louis Chabernaud ${ }^{7}$

\section{ABSTRACT}

To cite: Carbajal R, Lode Ayachi A, et al. Premedication practices for tracheal intubation in neonates transported by French medical transport teams: a prospective observational study. BMJ Open 2019;9:e034052. doi:10.1136/ bmjopen-2019-034052

- Prepublication history for this paper is available online. To view these files, please visit the journal online (http://dx.doi. org/10.1136/bmjopen-2019034052).

Received 04 September 2019 Revised 30 September 2019 Accepted 04 October 2019
Check for updates

(C) Author(s) (or their employer(s)) 2019. Re-use permitted under CC BY-NC. No commercial re-use. See rights and permissions. Published by BMJ.

For numbered affiliations see end of article.

Correspondence to Professor Ricardo Carbajal; ricardo.carbajal@trs.aphp.fr
Objectives Premedication practices for neonatal tracheal intubations have not yet been described for neonatal transport teams. Our objective is to describe the use of sedation/analgesia (SA) for tracheal intubations and to assess its tolerance in neonates transported by medical transport teams in France.

Setting This prospective observational study was part of the EPIPPAIN 2 project and collected around-the-clock data on SA practices in neonates intubated by all five paediatric medical transport teams of the Paris region during a 2-month period. Intubations were classified as emergent, semiemergent and non-emergent. Sedation level and conditions of intubation were assessed with the Ionus, Reactivity, Awareness and $\underline{\text { Conditions }}$ of intubation to $\underline{\text { Help }}$ in Endotracheal intubation Assessment (TRACHEA score). The scores range from 0 to 10 representing an increasing ladder from adequate to inadequate sedation, and from excellent to very poor conditions of intubation.

Participants 40 neonates intubated in 28 different centres.

Results The mean (SD) age was 34.9 (3.9) weeks, and $62.5 \%$ were intubated in the delivery room. 30/40 (75\%) of intubations were performed with the use of SA. In 18/30 $(60.0 \%)$ intubations performed with SA, the drug regimen was the association of sufentanil and midazolam. Atropine was given in 19/40 intubations. From the 16, 21 and 3 intubations classified as emergent, semiemergent and non-emergent, respectively, 8 (50\%), 19 (90.5\%) and 3 (100\%) were performed with SA premedication. $79.3 \%$ of intubations performed with SA had TRACHEA scores of 3 or less. $22 / 40(55 \%)$ infants had at least one of the following adverse events: muscle rigidity, bradycardia below 100/ min, desaturation below $80 \%$ and nose or pharynx-larynx bleeding. $7 / 24$ (29.2\%) of those who had only one attempt presented at least one of these adverse events compared with $15 / 16(93.8 \%)$ of those who needed two or more attempts $(p<0.001)$.

Conclusion SA premedication is largely feasible for tracheal intubations performed in neonates transported by medical transport teams including intubations judged as emergent or semiemergent.

Trial registration number NCT01346813; Results.
Strengths and limitations of this study

- First study using a bedside real-time observational approach to determine sedation/analgesia practices for tracheal intubation in neonates during intercentre transport.

- Notwithstanding challenging transport conditions, sedation/analgesia premedication was feasible during tracheal intubation in neonates even in some emergent situations.

- The ground for initial validity of the 'Tonus, Reactivity,

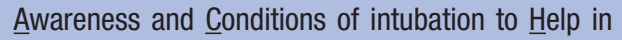
Endotracheal intubation Assessment' score to assess infant's responses and conditions of endotracheal intubation was set.

- The relative high frequency of adverse effects during neonatal tracheal intubation underlines the need to develop well-established sedation/analgesia protocols in this vulnerable population.

- The number of tracheal intubations was relatively low, most likely due to the development of noninvasive approaches to manage respiratory distress in these neonates.

\section{INTRODUCTION}

In the most developed countries, the regionalisation of perinatal care, including the coordination of obstetric and neonatal services within a network of perinatal centres, has highly contributed to the improvement of maternal and neonatal outcomes. ${ }^{1}$ Notwithstanding the increase of antenatal transfer and delivery at tertiary care centres of highrisk fetuses, some infants are delivered at primary and secondary settings and require transfer for higher levels of care. The practice of neonatal interfacility transport has dramatically evolved during the last two decades to provide state-of-the-art care outside tertiary centres. ${ }^{2}$ In order to establish the best practices for transport of newborns, Schwartz et al have determined, by consensus, 12 metrics 
considered as very important for transport; one of these is airway management. ${ }^{3}$

Endotracheal intubation is an essential procedure in airway management of high-risk neonates needing transport. ${ }^{4}$ It requires highly trained staff in order to perform it in the best conditions at the referring centre or during transport. Different organisations of paediatric and neonatal interfacility transport exist worldwide. ${ }^{5}$ In France, since the late " 70 s neonatal transfers have been carried out by specialised teams that include a physician (Service Mobile d'Urgence et de Réanimation -SMUR). ${ }^{56}$ These teams play a critical role in newborn stabilisation comprising endotracheal intubation. This invasive procedure is very painful and has been associated with laryngospasm, bronchospasm, haemodynamic changes and an increased risk of intracranial haemorrhage. ${ }^{7}$ Recent guidelines from the American Academy of Pediatrics (AAP) recommend, except for emergent intubation during resuscitation either in the delivery room or after acute deterioration or critical illness at a later age, the use of premedication for all endotracheal intubations in newborns. ${ }^{8}$ In spite of the need to provide effective sedation and/or analgesia, implementation of a systematic efficient premedication in neonatal intensive care units (NICUs) is still heterogeneous as illustrated by different studies. ${ }^{910}$ Although, premedication practices for neonatal tracheal intubation have been described in NICUS, ${ }^{11}$ to the best of our knowledge, these practices have not yet been described for neonatal transport teams.

The objective of this study was to describe the use of premedication for tracheal intubation and its efficacy and tolerance in neonates transported by all teams of a regional medical transport system in France.

\section{METHODS}

\section{Study transport teams}

This study was part of the EPIPPAIN 2 project. It was designed as a prospective observational study to collect around-the-clock data on sedation and analgesia practices in neonates transported by all five paediatric medical transport teams (Paediatric SMUR) of the Paris region (land area of $12012 \mathrm{~km}^{2}$ and 12.6 million inhabitants). Four transport teams were within university-affiliated hospitals and one within a community hospital. Medical and nurse coordinators were designated in each participating unit. Training material (PowerPoint presentation, posters and copies of the collection forms) was distributed and presented to healthcare providers from the units. Local coordinators and research assistants presented this material in each unit and copies were available so that the personnel had the opportunity to look at it before or during the study. No instructions were given to modify the standard of care for sedation and analgesia during intubation in transported neonates.

\section{Study infants}

Neonates were included if they were intubated and transported by the participating paediatric SMUR, and were either preterm neonates of less than 45 postconceptional weeks or term neonates less than 28 days. The recruitment period for each unit was 2 months. This duration was deemed sufficient to study the practices of all rotating personnel and to minimise temporal changes in clinical practices. The only exclusion criterion was the refusal of parents for the gathering of data on their infant. For each included infant, data were collected from the arrival of the paediatric SMUR in the referring unit, throughout all the transport and until the arrival of the neonate in the destination unit.

We collected, at the bedside and on real-time, data on patient demographics, type of respiratory support, sedatives and analgesics administered, use of neuromuscular blocking agents, physiological parameters and detailed conditions of endotracheal intubation. Premedication was defined as the use of intravenous central nervous system depressants. In order to assess the tolerance of the intubation by the neonate as well as the efficacy of sedation and/or analgesia premedication, an assessment score was developed prior to patient recruitment; it was based on previous studies describing sedation and conditions of intubation. ${ }^{12-16}$ This score was named the TRACHEA score which stands for 'Tonus, Reactivity, Awareness and Conditions of intubation to Help in Endotracheal intubation Assessment' (table 1). Although numeric values had been attributed to each option of every item, only the descriptors (without the values) were available for the transport teams performing the intubations. Values were added in the database during data entry. Total scores ranged from 0 to 10 where 0 represents adequate sedation with excellent conditions of intubation and 10 represents inadequate sedation with very poor conditions of intubation. The TRACHEA score was fulfilled prospectively only for the first attempt of intubation. Besides, the operator that performed the first intubation attempt as well as the staff member that assisted during the intubation assessed on a $0-10$ scale the pain and/or discomfort that they thought the infant felt during the intubation procedure where 0 represented no pain or discomfort and 10 the maximum pain or discomfort. The internal consistency of the three items of the TRACHEA score was assessed with the Cronbach's alpha coefficient ${ }^{17}$ which measures inter-relatedness among items and where values above 0.70 represent good inter-relatedness.

Research assistants and local coordinators completed all needed information from the patient files on a specific form. A clinical research assistant visited each transport unit once a week during the study period to assess recruitment of all patients by checking logbooks and to help with collection exhaustiveness of patient data.

\section{Intubation}

Only intubations performed by the medical transport team were included. The level of urgency of the 


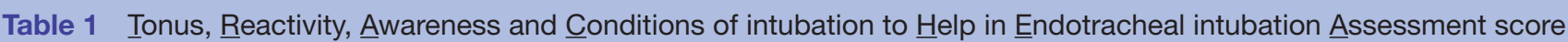

\section{Tonus (muscles of} extremities)

0. Totally hypotonic
1. Slightly hypotonic
2. Normal tonus
3. Hypertonic

Reactivity and awareness (during final positioning and intubation)

0. Deeply asleep not awaken by physical stimuli

1. Asleep but reacts slightly to physical stimuli

2. Asleep or sleepy but wakens up easily to physical stimulus

3. Spontaneously awake

4. Agitated, anxious, combative (defence or fighting movements)

\section{Conditions of intubation}

(vocal cords view and tube insertion)

0. Relaxed jaw AND abducted vocal cords AND no thoracic movements during tube insertion

1. Relaxed jaw AND abducted vocal cords AND slight thoracic movements during tube insertion

2. Moderate jaw resistance but opening is possible AND/OR vocal cords moving AND/OR slight or moderate coughing (or efforts to cough) during tube insertion

3. Contracted jaw (jaw opening is difficult or impossible) $\underline{\mathrm{OR}}$ closed vocal cords $\underline{\mathrm{OR}}$ intense coughing (or efforts to cough) $\mathrm{OR}$ blocking of the tube in the larynx intubation was assessed by the physician leading the transport team. This could be classified in three levels: (1) emergent, if the intubation needed to be carried out in less than $10 \mathrm{~min}$ after the decision of intubation because of the need of immediate cardio resuscitation or because of an acute clinical deterioration (2) semiemergent, if the intubation could be performed between 10 and $30 \mathrm{~min}$ after the decision of intubation and (3) non-emergent or deferred, if the intubation could be performed more than $30 \mathrm{~min}$ after the intubation decision. A member of the transport team not directly involved in the intubation collected bedside real-time data concerning this procedure.

Descriptive and summary statistics were performed. Results are presented as means with SD and medians with IQR for continuous variables, and as proportions for categorical variables. Comparisons of proportions were carried out with $\mathrm{X}^{2}$ test and Fisher correction if necessary. Data were analysed using SPSS V.17 (SPSS) software. P values below 0.05 were considered statistically significant.

\section{Patient and public involvement statement}

It was not appropriate or possible to involve patients or the public in the design, or conduct, or reporting, or dissemination of our research

\section{RESULTS}

Between May and August 2011, the 5 participating transport teams transferred 446 neonates and enrolled 40 neonates in this study on premedication for endotracheal intubation. These infants were recruited in 28 different centres including 8 level-1, 19 level-2 and 1 level-3 perinatal centres (the higher the level, the higher the degree of complexity). The enrolled neonates represented $100 \%$ of all eligible intubated neonates. Table 2 shows the demographic characteristics of these infants. The mean (SD) gestational age (GA) was 34.9 (3.9) weeks. A total of $37.5 \%$ were below 33 weeks GA, 32.5\% were 33-36 weeks GA and $30 \%$ term neonates. Of the enrolled neonates, 25 $(62.5 \%)$ were intubated in the delivery room.
Table 3 shows the characteristics of tracheal intubations performed in this population by the transport team. Overall, $40 \%$ of intubations were judged as emergent. It is worth to note that $92.5 \%$ of intubations were performed through the nasal route. Thirty out of 40 (75\%) intubations were performed with the use of sedation and/or analgesia premedication. The sedation and/or analgesia regimens were $2(6.7 \%)$ sufentanil +midazolam +suxamethonium, $16(53.3 \%)$ sufentanil +midazolam, $3(10.0 \%)$ sufentanil only, $3(10.0 \%)$ midazolam only, 5 (16.7\%) morphine only and 1 (3.3\%) propofol only. Atropine was given in 15/30 and in 4/10 intubations performed, respectively, with and without sedation and/or analgesia premedication (table 4). From the 16, 21 and 3 intubations classified as emergent, semiemergent and non-emergent, respectively, $8(50 \%), 19(90.5 \%)$ and 3 $(100 \%)$ were performed with sedation and/or analgesia premedication. Eight $(80 \%)$ out of 10 and $8(26.7 \%)$ out of 30 of the intubations in the groups without and with sedation/analgesia, respectively, were classified as emergent, $\mathrm{p}=0.007$. The mean $(\mathrm{SD})$ doses used for premedication were sufentanil $0.2(0.1) \mu \mathrm{g} / \mathrm{kg}$, midazolam 83 (4) $\mu \mathrm{g} / \mathrm{kg}$, suxamethonium 2.2 (1) $\mathrm{mg} / \mathrm{kg}$, morphine 80 (27) $\mu \mathrm{g} / \mathrm{kg}$ and propofol $2 \mathrm{mg} / \mathrm{kg}$. The TRACHEA score was prospectively fulfilled in 29/30 infants who received sedation and/or analgesia premedication and in 10/10 of those who did not. The Cronbach's coefficient for the three items was 0.80 ; the removal of items one by one yielded coefficients between 0.55 and 0.80 . Based on the items of the score, the authors empirically considered that the infant's responses and tolerance as well as the conditions of intubation could be considered as 'ideal or excellent' if the score was 0 or 1 , 'acceptable' if it was 2 or 3 and 'poor to very poor' if it was 4 to 10 . In the no sedation and/or analgesia group, 6 (60\%), $2(20 \%)$ and $2(20 \%)$ infants had a score of $0-1,2-3$ and 4 or more, respectively. In the sedation/analgesia group, the corresponding figures were, $9(31 \%), 14(48.3 \%)$ and 6 $(20.7 \%)$. Intubations were succeeded in only one attempt in $16 / 30(53.3 \%)$ and $8 / 10(80 \%)$ of neonates with and 
Table 2 Demographic characteristics of 40 neonates intubated by the medical transport team

\begin{tabular}{|c|c|}
\hline Characteristics & Value \\
\hline $\begin{array}{l}\text { Gestational age at birth, week, median } \\
\text { (IQR) }\end{array}$ & $35.1(31.9-38.5)$ \\
\hline \multicolumn{2}{|c|}{ Gestational age group at birth, week, no (\%) } \\
\hline $24-29$ & $4(10.0)$ \\
\hline 30-32 & $11(27.5)$ \\
\hline $33-36$ & $13(32.5)$ \\
\hline $37-42$ & $12(30.0)$ \\
\hline Birth weight, g, median (IQR) & $2282(1570-3005)$ \\
\hline Male, no (\%) & $28(70.0)$ \\
\hline $\begin{array}{l}\text { Age at transport team arrival }{ }^{*}, h \text {, } \\
\text { median (IQR) }\end{array}$ & $2.7(0.5-6.9)$ \\
\hline \multicolumn{2}{|l|}{ Apgar, median (IQR) } \\
\hline $1 \min (n=38)$ & $7.5(5.0-10)$ \\
\hline $5 \min (n=38)$ & $9.0(8.0-10.0)$ \\
\hline $\begin{array}{l}\text { Age at intubation, hour, median (IQR) } \\
(\mathrm{n}=38)\end{array}$ & $3.6(1.0-6.4)$ \\
\hline
\end{tabular}

Place of intubation, no (\%)

\begin{tabular}{lc} 
Delivery room & $25(62.5)$ \\
Neonatology department & $12(30.0)$ \\
$\begin{array}{l}\text { Other (maternity ward, emergency } \\
\text { department and transport vehicle) }\end{array}$ & $3(7.5)$ \\
$\begin{array}{l}\text { Reason for intubation†, No. (\%) } \\
\text { Respiratory distress }\end{array}$ & $31(77.5)$ \\
Neurologic disorder & $5(12.5)$ \\
Apnoea & $4(10.0)$ \\
Sepsis & $2(5.0)$ \\
Congenital heart disease & $2(5.0)$ \\
Tracheal tube replacement & $2(5.0)$ \\
Cardiac arrest & $1(2.5)$ \\
Died during transport & $1(2.5)$ \\
\hline
\end{tabular}

*Arrival of the transport team by the neonate.

†Someinfants had more than one reason.

without prior sedation/analgesia, $\mathrm{p}=0.136$. Table 4 shows all the individual scores, the level of urgency, the sedation and/or analgesia regimen as well as the pain/discomfort assessment scores during intubation. The correlation coefficient (Rho Spearman) between the TRACHEA scores and the operator's and assistant's assessments of pain/ discomfort were $0.755(p<0.001)$ and $0.569(p<0.001)$, respectively. Figure 1 shows the scatterplot of TRACHEA scores and pain/discomfort assessment performed by the operator and the assistant.

During the intubation procedure, 22 of the 40 $(55 \%)$ infants had at least one of the following adverse events: muscle rigidity, bradycardia below 100 beats per minute (bpm), desaturation below $80 \%$ and nose or
Table 3 Characteristics of 40 tracheal intubations performed in neonates by the medical transport team (SMUR)

\begin{tabular}{|c|c|}
\hline Characteristics & Value \\
\hline \multicolumn{2}{|l|}{ Level of urgency for intubation*, no (\%) } \\
\hline Emergent & $16(40.0)$ \\
\hline Semiemergent & $21(52.5)$ \\
\hline Non-emergent & $3(7.5)$ \\
\hline $\begin{array}{l}\text { Vascular access available at intubation, no } \\
(\%)\end{array}$ & $35(87.50)$ \\
\hline $\begin{array}{l}\text { Mask ventilation prior to tube insertion } \\
(\mathrm{n}=39) \text {, no }(\%)\end{array}$ & $32(82.05)$ \\
\hline Use of a Beaufils connectort ( $n=35)$, no $(\%)$ & $12(34.29)$ \\
\hline \multicolumn{2}{|l|}{ Route of access for intubation $(n=40)$, no $(\%)$} \\
\hline Nasal & $37(92.5)$ \\
\hline Oral & $3(7.5)$ \\
\hline $\begin{array}{l}\text { Delay between premedication and } \\
\text { laryngoscope insertion, min, median (IQR) }\end{array}$ & $3,0(2.0-5.0)$ \\
\hline $\begin{array}{l}\text { Duration of intubation } \neq \text {, min, }(n=34) \text {, median } \\
\text { (IQR) }\end{array}$ & $2.0(1.0-7.0)$ \\
\hline \multicolumn{2}{|c|}{ No of attempts to complete intubation, $(n=40)$, no $(\%)$} \\
\hline 1 & $24(60.0)$ \\
\hline 2 & $11(27.5)$ \\
\hline 3 or more & $5(12.5)$ \\
\hline \multicolumn{2}{|l|}{ Initial operator $(\mathrm{n}=39)$, no (\%) } \\
\hline Attending physician & $31(79.5)$ \\
\hline Resident & $2(5.1)$ \\
\hline Other§ & $6(15.4)$ \\
\hline \multicolumn{2}{|c|}{$\begin{array}{l}\text { Experience of initial operator, number of successful prior } \\
\text { intubations }(n=38)\end{array}$} \\
\hline$>50$ & 31 (81.6) \\
\hline 11 to 50 & $3(7.9)$ \\
\hline 1 to 10 & $1(2.6)$ \\
\hline None & $3(7.9)$ \\
\hline
\end{tabular}

*(1) Emergent, if the intubation needed to be carried out in less than 10 min after the decision of intubation because of the need of immediate cardio resuscitation or because of an acute clinical deterioration (2) semiemergent, if the intubation could be performed between 10 and $30 \mathrm{~min}$ after the decision of intubation and (3) non-emergent or deferred, if the intubation could be performed more than $30 \mathrm{~min}$ after the intubation decision. †Small tube that connect the endotracheal tube to the ventilator or an oxygen source to deliver oxygen during the intubation manoeuvre.

$\ddagger$ From laryngoscope insertion to its removal after tube insertion. §Midwives $\mathrm{n}=3$, anaesthesiology nurse $\mathrm{n}=3$.

SMUR, Service Mobile d'Urgence et de Réanimation.

pharynx-larynx bleeding. The analysis of these adverse events according to the number of attempts to complete the intubation showed that $7 / 24(29.2 \%)$ of those who had only one attempt presented at least one of these adverse events compared with 15/16 (93.8\%) of those 


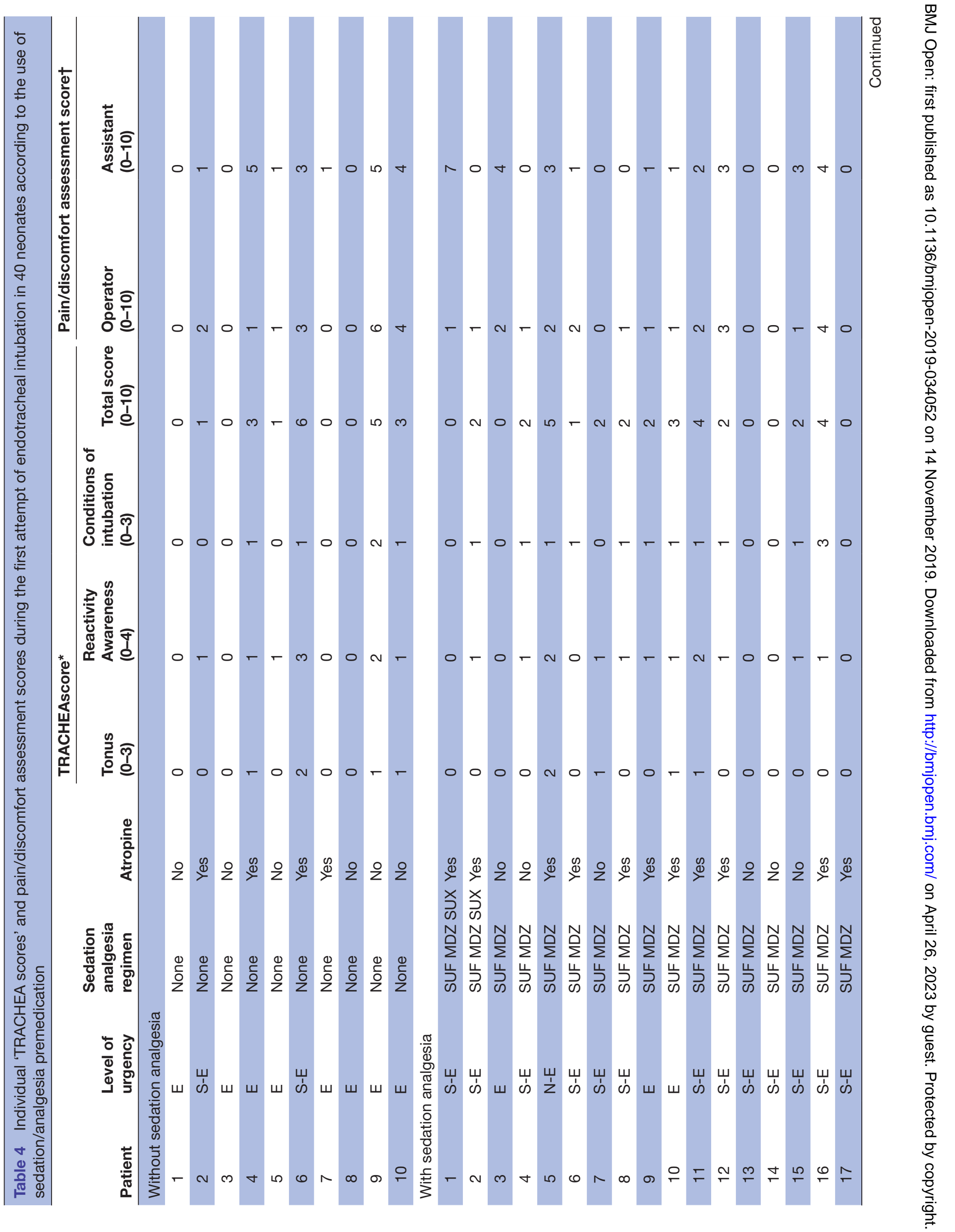




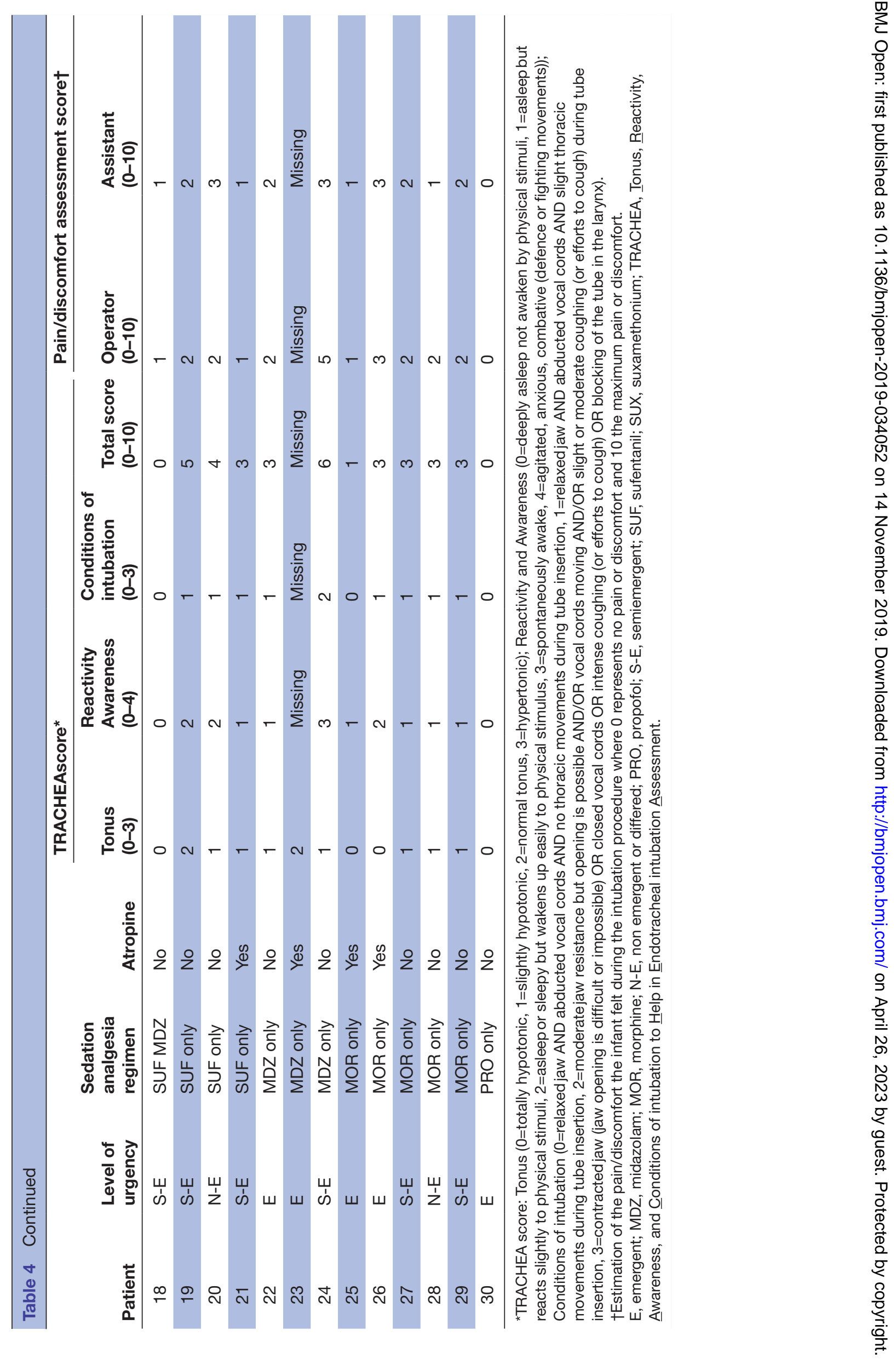


A

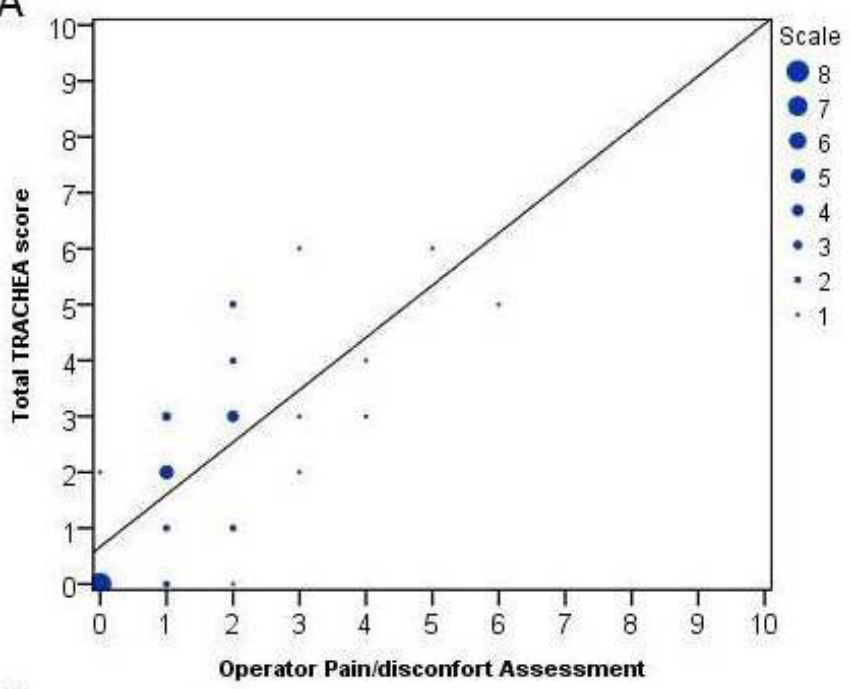

B

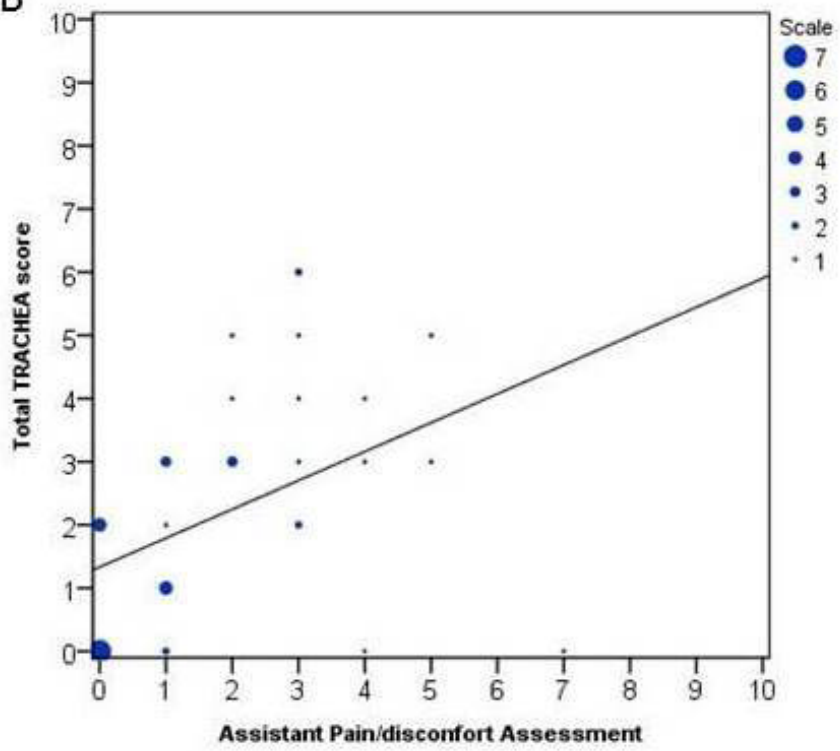

Figure 1 Correlations between TRACHEA scores and operator and assistant pain/discomfort assessments (0-10 scale) during the endotracheal intubation of 39 neonates (data missing for one neonate). The correlation coefficient (Rho Spearman) between the TRACHEA score and the operator $(A)$ and assistant assessment $(B)$ of pain or discomfort were $0.755(p<0.001)$ and $0.569(p<0.001)$, respectively. TRACHEA: Tonus, Reactivity, Awareness, and Conditions of intubation to Help in Endotracheal intubation Assessment.

who needed two or more attempts $(\mathrm{p}<0.001)$. In $12 / 19$ $(63.2 \%)$ infants who received atropine and in $12 / 21$ $(57.1 \%)$ who did not, intubation was succeeded in one attempt, $\mathrm{p}=0.698$. Information on bradycardia below 100 bpm was available for 34 infants; $1 / 17$ (5.9\%) infants who received atropine had bradycardia compared with $4 / 17$ $(23.5 \%)$ of those who did not receive it, $\mathrm{p}=0.152$. The adverse events are summarised in table 5 according to whether infants received sedation and/or analgesia prior to intubation.

\section{DISCUSSION}

To the best of our knowledge, this is the first study describing the premedication practices for tracheal intubation of neonates performed by regional transport teams. From a total of 446 neonates transported during the 2-month study period, 40 neonates were intubated by the transport teams. A total of $37.5 \%$ were 24-32 weeks GA, $32.5 \%$ were $33-36$ weeks GA and $30 \%$ term neonates; $62.5 \%$ were intubated in the delivery room. The level of urgency was described by the physician leading the transport team as emergent in 16/40 (40\%) of intubated neonates and in 21/40 (52.5\%) as semiemergent. Most neonates $(75 \%)$ were aged less than 6.4 hours at the time of intubation. Analgesia and/or sedation premedication was used in $75 \%$ of intubations.

We assessed the quality of intubation with a composite score named the TRACHEA score (table 1). To guarantee construct validity, all items were based on factors that have been described for decades as good indicators to assess intubation conditions. ${ }^{12-14} 18$ We aimed at a composite score to include the infant's responses and tolerance to intubation as well as the ease or difficulty encountered by the operator during the endotracheal intubation. We found a good internal consistency of the three score items reflected by a Cronbach's coefficient of 0.80 . The TRACHEA scores were correlated with an assessment of pain/discomfort carried out by the operator performing the intubation and the staff member who assisted with the intubation; correlations scores were 0.755 and 0.569 , respectively. These data constitute the ground for initial validity of this score. Our data suggest that sedation and conditions of intubation in infants who received sedation and/or analgesia were good as $79.3 \%$ of intubations performed in these infants yielded scores of 3 or below on a $0-10$ scale. It may be disturbing to see that $53 \%$ and $80 \%$ of intubations were succeeded in one attempt in the groups with and without sedation/analgesia, respectively. However, the authors consider that it was not relevant to compare intubations with and without sedation/analgesia premedication as these two groups were not comparable; for example, $80 \%$ and $26.7 \%$ of the intubations were considered emergent in the groups without and with sedation/analgesia, respectively; this clinical status may have an impact on the infants' reactions to intubation. Validated tools to assess sedation level and conditions of intubation are necessary to compare different premedication strategies. Recently, de Kort et al underlined, in a systematic review, the importance of assessing the sedation level prior to neonatal intubation so that intubation starts only after reaching an adequate level of sedation. ${ }^{19}$ To extend the utility of the TRACHEA score, we suggest that the first two items, 'Tonus' and 'Reactivity and Awareness' be used to assess the sedation level immediately prior to intubation so that laryngoscopy and tube insertion only start if the addition of the values of these two items is $0-1$.

Different drug regimens were used to premedicate these neonates reflecting a lack of consensus on which 
Table 5 Adverse effects observed during intubation according to whether the infant received sedation and/or analgesia for intubation

\begin{tabular}{|c|c|c|c|}
\hline & \multicolumn{2}{|c|}{ Use of sedation and/or analgesia, no (\%) } & \multirow[b]{2}{*}{ P value* } \\
\hline & Yes $(n=30)$ & No $(n=10)$ & \\
\hline Bradycardia <100 bpm, $(\mathrm{n}=34) \dagger$ & $2 / 25(8.0)$ & $3 / 9$ (33.3) & 0.102 \\
\hline Hypotension $\ddagger$ at $5 \mathrm{~min},(n=33=) \dagger$ & $9 / 26(34.6)$ & $1 / 7(14.3)$ & 0.397 \\
\hline Muscular rigidity, $(n=40)$ & $2 / 30(6.7) \S$ & $0 / 10(0.0)$ & 1.0 \\
\hline
\end{tabular}

${ }^{*} X^{2}$ with Fisher correction.

†Data on adverse events were not available for all neonates. łBelow the 10th percentile for gestational age (From Kent et al). ${ }^{44}$ $\S$ These two infants received sufentanil, midazolam and atropine.

drugs to use. ${ }^{8}$ Sufentanil and midazolam were the most frequently used medications; from the 30 neonates who were premedicated, $21(70 \%)$ received sufentanil and $21(70 \%)$ received midazolam with $18(60 \%)$ neonates receiving both of these drugs. Although data on the efficacy and safety of sufentanil in neonates are still scarce, this drug has reached a wide use in French NICUs during the last decade. Durrmeyer et al reported the use of sufentanil in 13/51 (25\%) neonates who were premedicated for tracheal intubation in French NICUs in 2005 and $2006 .{ }^{9}$ An epidemiological study on sedation and analgesia practices in European countries showed that sufentanil was used in $52.5 \%$ of ventilated neonates who received sedation analgesia in France in 2012 and $2013 .{ }^{20}$ Indeed, sufentanil was used almost exclusively in France and Poland in that study. Seguin et al showed that an intravenous loading dose $(0.2 \mu \mathrm{g} / \mathrm{kg})$ of sufentanil followed by a continuous infusion of $0.05 \mu \mathrm{g} / \mathrm{kg} /$ hour was well tolerated haemodynamically and appeared to provide adequate analgesia/ sedation in neonates receiving mechanical ventilation. ${ }^{21}$ Recently, in a study comparing premedication with atropine-propofol versus atropine-atracurium-sufentanil for intubation in neonates, the frequency of prolonged desaturation $(<80 \%$ for $>60$ s) did not differ significantly between groups, but in the atropine-atracurium-sufentanil group, the procedure duration was shorter and the time to respiratory recovery was longer. ${ }^{22}$

Midazolam was as frequently used as sufentanil. In a prospective survey conducted in 2001 in 75 French neonatal and paediatric intensive care units regarding intubation practices, it was found that midazolam was the main drug used in neonates whereas older children mainly received propofol. ${ }^{23}$ The wide popularity of midazolam for intubations in neonates contrasts with the lack of evidence sustaining its use. A randomised controlled trial studying midazolam and atropine as a premedication prior to intubation was prematurely interrupted because of frequent severe adverse events. ${ }^{24}$ A Cochrane review concluded that there were insufficient data to promote the use of intravenous midazolam infusion as a sedative for neonates undergoing intensive care. ${ }^{25} \mathrm{~A}$ report from the AAP on premedication for non-emergency endotracheal intubation in the neonate stated that midazolam should not be used in preterm infants, but it can be considered for use in the term or older infant as part of the premedication sequence for elective intubation in the NICU. ${ }^{8}$ Notwithstanding the discouraging results of previous studies, a recent randomised trial assessed nasal administration of midazolam (nMDZ) and concluded that $\mathrm{nMDZ}$ was more effective than nasal ketamine to adequately sedate neonates requiring intubation in the delivery room. ${ }^{26}$ The haemodynamic and respiratory effects of both drugs were comparable. Morphine alone was used for sedation and/or analgesia premedication in five infants with a mean dose of $80 \mu \mathrm{g} / \mathrm{kg}$. The use of morphine for endotracheal intubation premedication raises concerns because it has been showed that it has a delayed onset of action, ${ }^{27}$ that even at doses as high as 200 or $300 \mu \mathrm{g} / \mathrm{kg}$ its efficacy to obtain excellent intubation conditions is poor, ${ }^{27} 28$ and that it elicits a prolonged depression of the electrocortical background activity. ${ }^{29}$

Fifteen out of 30 neonates who received sedation and/or analgesia premedication for intubation were given atropine prior to intubation. Since bradycardia may occur during intubation due to the physiological activation of the vagus nerve or by the pharmacological action of several drugs used for sedation and anaesthesia, atropine has been used to prevent or reduce this bradycardia. ${ }^{30}$ However, its use for intubation premedication in neonates is still controversial. Kumar et al stated that vagolytic agents should be considered for intubation in neonates ${ }^{8}$ whereas a review by Jones concluded that the use of atropine for intubation premedication is more suitable for children older than 1 month or in children being intubated with sepsis. ${ }^{31}$ Atropine seems to protect against bradyarrhythmias. ${ }^{8}$ We did not find significant differences in the rate of bradycardia in infants who received atropine or did not, but the limited number of patients precludes formal conclusions.

Only two infants received succinylcholine (also known as suxamethonium) prior to intubation. Succinylcholine has both a rapid onset and a short duration of action. ${ }^{8}$ Recent guidelines state that the use of muscle relaxants should be considered for intubation premedication in neonates. ${ }^{8}$ 
Although intubations were performed in 28 different places with $92.5 \%$ of them being emergent or semiemergent, sedation and/or analgesia premedication was given in $75 \%$ of intubations. This shows that administering sedation and analgesia for neonatal intubations is usually feasible even in critical situations. It seems obvious that during extensive resuscitation at birth of neonates requiring intensive cardiorespiratory support, premedication for intubation would be nonsense. ${ }^{32}$ Intubation without premedication may also be acceptable during resuscitation or after acute deterioration or critical illness at a later age. ${ }^{8}$ For other situations, the risk/ benefit ratio of premedication should be carefully assessed as several trials have demonstrated that the use of premedication for intubation of the newborn significantly improves intubating conditions, decreases the time and number of attempts needed to complete the intubation procedure, and minimises the potential for intubation-related airway trauma. ${ }^{33-36}$ The AAP recommends that except for emergent intubations premedication should be used for all endotracheal intubations in newborns. ${ }^{8}$ We consider that the term emergent intubation needs to be better defined in order to determine within which time frame an intubation is considered emergent. In our study, we used a predefined time frame of less than $10 \mathrm{~min}$ after the decision of intubation to characterise an emergent intubation. Though arbitrary, this delay empirically corresponds to a procedure that has to be performed in a relatively short time.

Of note, around $80 \%$ of intubations were performed by highly trained physicians who had already performed more than 50 intubations. Eighty-seven per cent of intubations were succeeded in one or two attempts. The most widely route used was nasotracheal $(92.5 \%)$, which corresponds to French practices for neonatal intubations. The choice of the oral or nasal route for intubation is usually determined by an institution's customary practice or predominant practices in a country. A systematic review undertaken to compare the complications of oral and nasal routes in neonates found only two eligible randomised trials. ${ }^{37}$ These two trials did not demonstrate significant differences between the oral and nasal route of intubation for mechanically ventilated neonates. The rate of failure to intubate using the nasal route was higher in one study. One study found that post extubation atelectasis occurred more frequently in nasally intubated infants who weighed less than $1500 \mathrm{~g}$. The rates of malposition of the tube at the initial intubation, accidental extubation, tube blockage, reintubation after extubation, septicaemia, clinical infection and local trauma (nasal erosion or palatal groove) were not significantly different for the two groups. ${ }^{37}$ Lenclen et al performed a study on orotracheal and nasotracheal performance during training on a neonatal mannequin. ${ }^{38}$ They found that the orotracheal route had higher success rate and lower duration for intubation compared with the nasotracheal route.

Although most tracheal intubations were performed by very experienced staff, adverse events were very frequent (table 5). The most common adverse event was desaturation. This is in line with data reported in the literature. ${ }^{39}$ While hypotension seemed to be more frequent in infants who received sedation and/or analgesia, the difference was not statistically significant probably due to the limited number of cases. Given the deleterious effect that these may have on the neonate, it is of the outmost importance to develop strategies to reduce these adverse events. Hatch et al have studied different interventions to improve patient safety during intubation in the NICU and found that the implementation of a standardised checklist for intubation made the greatest impact to reduce adverse events. ${ }^{40}$ In a prospective multi-institutional paediatric observational study, an increasing number of tracheal intubation attempts was independently associated with desaturation and intubation adverse events in critically ill children with acute respiratory failure. ${ }^{41}$ Thoughtful selection of the initial intubating provider and optimising intubating conditions are important considerations to maximise the chance for first attempt success in order to optimise patient safety. ${ }^{41}$ In our study, adverse events during intubation occurred in almost all (93.8\%) infants that needed two or more attempts to complete intubation. In a retrospective study, Sauer et al showed that increased intubation attempts were associated with increased incidence of severe intraventricular haemorrhage in infants with birth weight less than $750 \mathrm{~g}$ and in infants less than $1500 \mathrm{~g}$ who were intubated only in the delivery room. ${ }^{42}$

Our study has some limitations. First, the number of intubations studied was relatively low, notwithstanding a period of data collection of 2 months for each of the five transport teams. This reflects a change in the approach of the neonate with respiratory distress where recent guidelines recommend the use of noninvasive ventilation as the first approach in premature infants. ${ }^{43}$ Due to the limited number of intubations, the evaluation of the impact of sedation and/or analgesia premedication on the rate of adverse events is difficult. Second, data were collected by the same team that practiced the intubations. It was not considered feasible to have other people collect the data for interventions that occurred 24 hours a day. However, data were collected into standardised questionnaires and by a member of the transport team that did not participate in the intubation. Finally, the standardised observation period after the intubation was limited to $15 \mathrm{~min}$. Nonetheless, the clinical observation was obviously continued until the infant arrived in the receiving hospital.

In conclusion, this study showed that sedation and/or analgesia premedication is largely feasible for tracheal intubations performed in neonates transported by a medical transport team. Fifty and $90.5 \%$ of intubations judged as emergent or semiemergent, respectively, were performed with sedation and/or analgesia premedication.

\section{Author affiliations}

${ }^{1}$ Service des Urgences Pédiatriques, Hôpital Trousseau, Paris, France ${ }^{2}$ Médecine Sorbonne Université, INSERM UMR 1153 Obstetrical, Perinatal and Pediatric Epidemiology Research Team (EPOPé), Paris, France

${ }^{3}$ Neonatal Transport Team, SMUR Pédiatrique, Hôpital Robert Debré, SAMU de Paris (AP-HP), Paris, France

${ }^{4}$ Neonatal Transport Team, SMUR Pédiatrique, SAMU de Seine Saint Denis (AP-HP), Montreuil, France 
${ }^{5}$ Neonatal Transport Team, SMUR Pédiatrique Necker, Hôpital Necker, SAMU de Paris (AP-HP), Paris, France

${ }^{6}$ Neonatal Transport Team, SMUR Pédiatrique, SAMU du Val d'Oise, Pontoise, France ${ }^{7}$ Neonatal Transport Team, SMUR Pédiatrique, Hôpital Antoine Béclère, SAMU des Hauts de Seine, Hôpitaux Universitaires Paris-Sud (AP-HP), Clamart, France ${ }^{8}$ Paediatric Emergency Department, Assitance Publique-Hôpitaux de Paris, Paris, France

${ }^{9}$ INSERM UMR 1153 Obstetrical, Perinatal and Pediatric Epidemiology Research Team (EPOPé), Paris, France

${ }^{10}$ Centre National de Ressources de Lutte Contre la Douleur, Hopital Armand Trousseau, Paris, France

Acknowledgements We gratefully acknowledge the contributions of the physicians, nurses and other healthcare providers at the participating institutions.

Contributors RC and J-LC have full access to all of the data in the study and take responsibility for the integrity of the data and the accuracy of the data analysis. Study concept and design: RC, NL, AA and J-LC. Acquisition of data: RC and EC. Analysis and interpretation of data: RC, NL, AA, JL-C and JR. First Draft of the manuscript: RC, NL, AA and JL-C. Critical revision of the manuscript for important intellectual content: RC, NL, AA, OC, VH-L, KK, AN, EC, JR, PC and J-LC. Statistical analysis: RC and JR. Obtained funding: RC. Administrative, technical or material support: RC, EC and PC. Study supervision: RC, EC and PC. Final approval: RC, NL, $A A, O C, V H-L, K K, A N, E C, J R, P C$ and J-LC. Agreement with all aspects of the work: RC, NL, AA, OC, VH-L, KK, AN, EC, JR, PC and J-LC.

Funding This study was supported by a grant from the CNP Foundation (Caisse Nationale de Prevoyance-Assurances, Paris, France) and a grant from the Programme Hospitalier de Recherche Clinique Regional (PHRC regional) 2012 with the file number 136 .

\section{Competing interests None declared.}

Ethics The study protocol was reviewed by the local Committee for the Protection of Human Subjects. Since this was an observational study with no changes in the standard of care, Human Subjects committee established that further approvals were not required according to French law. According to this law, a letter describing the data collection was distributed to parents and they had the possibility of refusing the collection of data regarding their child. The protocol was also approved by the French « Comité Consultatif sur le Traitement de l'Information en matière de Recherche dans le domaine de la Santé » (CCTRIS). The computerised data collection was approved by the French Data Protection Authority (Commission Nationale de l'Informatique et des Libertés).

Provenance and peer review Not commissioned; externally peer reviewed. Data availability statement № data are available.

Open access This is an open access article distributed in accordance with the Creative Commons Attribution Non Commercial (CC BY-NC 4.0) license, which permits others to distribute, remix, adapt, build upon this work non-commercially, and license their derivative works on different terms, provided the original work is properly cited, appropriate credit is given, any changes made indicated, and the use is non-commercial. See: http://creativecommons.org/licenses/by-nc/4.0/.

ORCID iD

Ricardo Carbajal http://orcid.org/0000-0002-3616-1549

\section{REFERENCES}

1 McCormick MC, Shapiro S, Starfield BH. The regionalization of perinatal services. Summary of the evaluation of a national demonstration program. JAMA 1985;253:799-804

2 Stroud MH, Trautman MS, Meyer K, et al. Pediatric and neonatal interfacility transport: results from a national consensus conference. Pediatrics 2013:132:359-66.

3 Schwartz HP, Bigham MT, Schoettker PJ, et al. Quality metrics in neonatal and pediatric critical care transport: a national Delphi project. Pediatr Crit Care Med 2015;16:711-7.

4 Fenton AC, Leslie A, Skeoch CH. Optimising neonatal transfer. Arch Dis Child Fetal Neonatal Ed 2004;89:F215-9.

5 RND R, Langford S, Chabernaud JL, et al. Newborn transport around the world. Semin Neonatol 1999;4:219-35.

6 Chabernaud JL. [Organization and execution of transportation for the newborn]. Soins Pediatr Pueric 1998:3-7.
7 Marshall TA, Deeder R, Pai S, et al. Physiologic changes associated with endotracheal intubation in preterm infants. Crit Care Med 1984;12:501-3.

8 Kumar P, Denson SE, Mancuso TJ, et al. Premedication for nonemergency endotracheal intubation in the neonate. Pediatrics 2010;125:608-15.

9 Durrmeyer X, Daoud P, Decobert F, et al. Premedication for neonatal endotracheal intubation: results from the epidemiology of procedural pain in neonates study. Pediatr Crit Care Med 2013:14:e169-75.

10 Chaudhary R, Chonat S, Gowda H, et al. Use of premedication for intubation in tertiary neonatal units in the United Kingdom. Paediatr Anaesth 2009;19:653-8.

11 Ancora G, Lago P, Garetti E, et al. Evidence-Based clinical guidelines on analgesia and sedation in newborn infants undergoing assisted ventilation and endotracheal intubation. Acta Paediatr 2019;108:208-17.

12 Hans P, Brichant JF, Hubert B, et al. Influence of induction of anaesthesia on intubating conditions one minute after rocuronium administration: comparison of ketamine and thiopentone. Anaesthesia 1999;54:276-9.

13 Cooper R, Mirakhur RK, Clarke RS, et al. Comparison of intubating conditions after administration of ORG 9246 (rocuronium) and suxamethonium. Br J Anaesth 1992;69:269-73.

14 Naulaers G, Deloof E, Vanhole C, et al. Use of methohexital for elective intubation in neonates. Arch Dis Child Fetal Neonatal Ed 1997;77:F61-4

15 Ramsay MA, Savege TM, Simpson BR, et al. Controlled sedation with alphaxalone-alphadolone. Br Med J 1974;2:656-9.

16 Sessler CN, Gosnell MS, Grap MJ, et al. The Richmond AgitationSedation scale: validity and reliability in adult intensive care unit patients. Am J Respir Crit Care Med 2002;166:1338-44.

17 Raykov T, Marcoulides GA. Thanks coefficient alpha, we still need you! Educ Psychol Meas 2019;79:200-10.

18 Viby-Mogensen J, Engbaek J, Eriksson LI, et al. Good clinical research practice (GCRP) in pharmacodynamic studies of neuromuscular blocking agents. Acta Anaesthesiol Scand 1996;40:59-74.

19 de Kort EHM, Halbmeijer NM, Reiss IKM, et al. Assessment of sedation level prior to neonatal intubation: A systematic review. Paediatr Anaesth 2018;28:28-36.

20 Carbajal R, Eriksson M, Courtois E, et al. Sedation and analgesia practices in neonatal intensive care units (EUROPAIN): results from a prospective cohort study. Lancet Respir Med 2015;3:796-812.

21 Seguin JH, Erenberg A, Leff RD. Safety and efficacy of sufentanil therapy in the ventilated infant. Neonatal Netw 1994;13:37-40.

22 Durrmeyer X, Breinig S, Claris O, et al. Effect of atropine with propofol vs atropine with Atracurium and sufentanil on oxygen desaturation in neonates requiring Nonemergency intubation: a randomized clinical trial. JAMA 2018;319:1790-801.

23 Simon L, Trifa M, Mokhtari M, et al. Premedication for tracheal intubation: a prospective survey in 75 neonatal and pediatric intensive care units*. Crit Care Med 2004;32:565-8.

24 Attardi DM, Paul DA, Tuttle DJ, et al. Premedication for intubation in neonates. Arch Dis Child Fetal Neonatal Ed 2000;83:160Fc-160.

$25 \mathrm{Ng} \mathrm{E}$, Taddio A, Ohlsson A. Intravenous midazolam infusion for sedation of infants in the neonatal intensive care unit. Cochrane Database Syst Rev 2012;6.

26 Milési C, Baleine J, Mura T, et al. Nasal midazolam vs ketamine for neonatal intubation in the delivery room: a randomised trial. Arch Dis Child Fetal Neonatal Ed. 2018;103:F221-6. May.

27 Norman E, Wikström S, Hellström-Westas L, et al. Rapid sequence induction is superior to morphine for intubation of preterm infants: a randomized controlled trial. J Pediatr 2011;159:893-9.

28 Pereira e Silva Y, Marcatto JdeO, Marcatto JdeO, et al. Morphine versus remifentanil for intubating preterm neonates. Arch Dis Child Fetal Neonatal Ed 2007:92:F293-4.

29 Norman E, Wikström S, Rosén I, et al. Premedication for intubation with morphine causes prolonged depression of electrocortical background activity in preterm infants. Pediatr Res 2013;73:87-94.

30 Andriessen P, Janssen BJA, Berendsen RCM, et al. Cardiovascular autonomic regulation in preterm infants: the effect of atropine. Pediatr Res 2004;56:939-46.

31 Jones P. The therapeutic value of atropine for critical care intubation Arch Dis Child 2016;101:77-80.

32 Perlman JM, Wyllie J, Kattwinkel J, et al. Neonatal resuscitation: 2010 international consensus on cardiopulmonary resuscitation and emergency cardiovascular care science with treatment recommendations. Pediatrics 2010;126:e1319-44.

33 Roberts KD, Leone TA, Edwards WH, et al. Premedication for nonemergent neonatal Intubations: a randomized, controlled 
trial comparing atropine and fentanyl to atropine, fentanyl, and mivacurium. Pediatrics 2006;118:1583-91.

34 Carbajal R, Eble B, Anand KJS. Premedication for tracheal intubation in neonates: confusion or controversy? Semin Perinatol 2007;31:309-17.

35 Dempsey EM, Al Hazzani F, Faucher D, et al. Facilitation of neonatal endotracheal intubation with mivacurium and fentanyl in the neonatal intensive care unit. Arch Dis Child Fetal Neonatal Ed 2006;91:F279-82.

36 Ghanta S, Abdel-Latif ME, Lui K, et al. Propofol compared with the morphine, atropine, and suxamethonium regimen as induction agents for neonatal endotracheal intubation: a randomized, controlled trial. Pediatrics 2007:119:e1248-55.

37 Spence K, Barr P. Nasal versus oral intubation for mechanical ventilation of newborn infants. Cochrane Database Syst Rev 2000:CD000948.

38 Lenclen R, Narcy P, Castela F, et al. [Evaluation of an educational intervention on the standard of neonatal resuscitation: orotracheal versus nasotracheal intubation]. Arch Pediatr 2009;16:337-42.
39 Hatch LD, Grubb PH, Lea AS, et al. Endotracheal intubation in neonates: a prospective study of adverse safety events in 162 infants. J Pediatr 2016;168:e66:62-6.

40 Hatch LD, Grubb PH, Lea AS, et al. Interventions to improve patient safety during intubation in the neonatal intensive care unit. Pediatrics 2016;138:e20160069.

41 Lee JH, Turner DA, Kamat P, et al. The number of tracheal intubation attempts matters! a prospective multi-institutional pediatric observational study. BMC Pediatr 2016;16:58.

42 Sauer CW, Kong JY, Vaucher YE, et al. Intubation attempts increase the risk for severe intraventricular hemorrhage in preterm Infants-A retrospective cohort study. J Pediatr 2016;177:108-13.

43 Sweet DG, Carnielli V, Greisen G, et al. European Consensus Guidelines on the Management of Respiratory Distress Syndrome 2016 Update. Neonatology 2017;111:107-25.

44 Kent AL, Meskell S, Falk MC, et al. Normative blood pressure data in non-ventilated premature neonates from 28-36 weeks gestation. Pediatr Nephrol 2009;24:141-6. 